\title{
Bulanık VIKOR Yöntemine Dayalı Personel Seçim Süreci
}

\author{
Based on Fuzzy VIKOR Approach to Personnel Selection Process
}

Ayşe YILDIZ1 ${ }^{1}$ Muhammed DEVECi ${ }^{2}$

\begin{abstract}
ÖZET
Son yıllarda kaliteli personelin seçimi firmalar için önemli bir başarı faktörü ve stratejik bir karar haline gelmiştir. Ancak bu karar genellikle karmaşıktır ve belirsiz bir ortamda verilir. Birbirleriyle çelişen birçok niceliksel ve niteliksel kriteraynıanda dikkate alınmalıdır. Bulanık çok kriterli karar verme yöntemleri bu sorunlara çözüm olmak amacıyla geliştirilmiştir. Bu yöntemler karar vericilerin tercihlerindeki belirsizliği yansıtıp birçok kriteri aynı anda değerlendirir.Çok kriterli karar verme yöntemlerinden biri olan bulanık VIKOR yöntemi, bulanık mantık teorisini kullanıp çoğunluk için grup faydasını maksimize ederek ve rakip seçenek için bireysel pişmanlığı minimize ederek uzlaştırıcı bir çözüm oluşturur. Bu çalışmada bulanık VIKOR yöntemi kullanılarak bir teknoloji firmasının personel seçim süreci incelenmiştir.Bu süreçte beş aday üç karar verici tarafından beş kritere göre değerlendirilmiş ve hesaplanan indekslere göre bir sıralama yapılmıştır. Çalışma, bulanık VIKOR yönteminin personel seçiminde etkin bir yöntem olarak kullanılabileceğini göstermiştir.
\end{abstract}

Anahtar Kelimeler:Bulanık mantık, bulanık VIKOR, personel seçimi

\section{GíRiş}

Günümüz yöneticilerinin yerine getirmesi gereken en önemli fonksiyonlardan biri karar vermedir. Ancak küreselleşme olgusu, belirsizlik ve hızı ıeğişim karar verme sürecini daha karmaşık, daha fazla boyutlu ele alınması gereken bir yapıya dönüştürmüştür. Kararların artık gruplar halinde alındığı, sadece sayısal verilerin değil sayısallaştırılamayan verilerin de önem kazandığı gözlemlenmektedir. Bu değişim özellikle personel seçimi gibi karar süreçlerinde de kendini göstermektedir. Personel seçimi sadece deneyimsel tecrübelerle değil, farklı kriterlerin, farklı kişilerin, farklı değerlendirmelerin ışığı altında yapılması gereken bir faaliyet olarak görülmelidir. Bununla birlikte bu süreçte bazı sorunlarla karşılaşılmaktadır. Bu sorunlardan birincisi çoğunlukla aynı

\begin{abstract}
In recent years, the selection of high quality personnel has become an important success factor and a strategic decision for companies. However, this decision is generally complex and made in vague environment. Many conflicting quantative and qualitative criteria should be taking into account at the same time. Fuzzy multi criteria decision making methods are developed in order to solve these problems. These methods evaluate many criteria at the same time, with various weights reflecting vague of preferences of the decision makers. The fuzzy VIKOR method which is one of the multi criteri decision making method determines a compromise solution, providing a maximum group utility for the majority and minimum of an individual regret for the opponent based on the fuzzy logic theory. In this study, the personnel selection process is examined for one technolgy company by applying the Fuzzy VIKOR method. In this process, five canditates are evaluated according to five criteria by three decision makers and are ranked in accordance with the calculated indexes.The study showed that fuzzy VIKOR method can be used as an effective method for personnel selection.
\end{abstract}

Keywords: Fuzzy logic, Fuzzy VIKOR, personnel selection

ölçü birimine sahip olmayan birçok farklı kriterin aynı anda dikkate alınmasından ve tüm kriterleri aynı anda sağlayan çözümün olmamasından doğmaktadır (Oprivoric ve Tzeng, 2004). Değerlendirmede karşılaşılan diğer bir sorun ise kriterlerden bazılarının kendine güven, sosyal ilişkilere yatkınlık gibi sayısal değerlerle ifade edilemeyen kriterleri kapsamasıdır. Ayrıca bu kriterlere düşük, çok düşük, yüksek, çok yüksek gibi dilsel olarak ifade edilebilecek değerler atanması gerekir (Zadeh, 1975). Bulanık mantığa dayalı çok kriterli karar verme teknikleri bu sorunlara çözüm olarak, çok sayıda nicel ve niteliksel birçok kriteri bir arada dikkate alan ve bu kriterlere göre belirlenen alternatifleri birlikte değerlendirerek eşanlı çözebilen uzlaşmacı yöntemlerdir (Kelemenis ve Askounis,2010: 4999-5000). 
$\mathrm{Bu}$ nedenle literatürde personel seçiminde bu yöntemlerin çok kullanıldığı görülmektedir. Analitik Hiyerarşik Process (AHP) (Saaty, 1980), Analitik Ağ Süreci (ANP) (Saaty, 1996), Basit Toplamsal Ağırlık (SAWSimple Additive Weigthing) (Fishburn, 1967), TOPSIS (Technique for Order Preference by Similarity to Ideal Solution) (Hwang and Yoon, 1981) ve VIKOR (Sırpça: VlseKriijumsko Optimizacijo I Kompromisno Resenje) (Opricovic, 1998) bulanık küme teorisiyle birleştirilen ÇKKV tekniklerinden bazılarıdır.

\section{LITERATÜR}

Personel seçim süreci farklı kriterlerin, kriterlerin farklı göreli ağırlıklarının ve bu değerlendirmelerin sayısal ifadelerden çok dilsel kavramlarla ifade edildiği karmaşık ancak bir o kadar da önemli bir süreçtir. Bu nedenle bu sürecin geliştirilmesine yönelik yeni yöntemler, farklı çalışmalar yapılmaktadır. Bu çalışmalardan bazıları Tablo 1'de kısaca gösterilmiştir:

Tablo 1: Personel Seçiminde ÇKKV Tekniklerini Kullanan Çalışmalar

\begin{tabular}{|l|l|l|}
\hline Yazar(lar) & Seçim Konusu & Kullanılan Yöntem(ler) \\
\hline Chen (2000) & Sistem Mühendisi & Bulanık Mantık \\
\hline Saghafian ve Hejazi, 2005 & Üniversite Profesörü & Bulanık Mantık \\
\hline Ecer (2006) & Satış Elemanı & Bulanık TOPSIS \\
\hline Özkan (2007) & AR-GE Personel Seçimi & AHP, ELECTRE, TOPSIS \\
\hline Dereli ve Diğerleri (2010) & Endüstri Mühendisi & Bulanık PROMETHEE \\
\hline Afshari ve Diğerleri (2010) & Bilgi Teknoloji Uzmanı & SAW \\
\hline Nasab ve Malkhalifeh (2010) & Sistem Mühendisi & Aralıklı Bulanık Yöntemi \\
\hline Kelemenis ve Askouris (2010) & Bilişim Uzmanı & Bulanık TOPSIS \\
\hline Dursun ve Karsak (2010) & Endüstri Mühendisi & Çok Kriterli Bulanık Mantık \\
\hline Başkaya ve Öztürk (2011) & Satış Elemanı & Bulanık TOPSIS \\
\hline Anisseh ve Nosnah (2011) & $\begin{array}{l}\text { Üniversitede Yükseltilecek } \\
\text { Profesörler }\end{array}$ & Bulanık TOPSIS \\
\hline Ersoylu (2011) & $\begin{array}{l}\text { Havacılık Okuluna Öğrenci } \\
\text { Secimi }\end{array}$ & $\begin{array}{l}\text { Bulanık AHP ve Bulanık } \\
\text { VIKOR }\end{array}$ \\
\hline Kabak ve Kazançoğlu (2012) & $\begin{array}{l}\text { Askeri Okulda Öğretmen } \\
\text { Adayları }\end{array}$ & Bulanık AHP \\
\hline El-Santawy (2012) & Eğitim Alacak Personel & VIKOR \\
\hline $\begin{array}{l}\text { Kabak, Burmaoğlu ve } \\
\text { Kazançoğlu (2012) }\end{array}$ & Profesyonel Nişancı & $\begin{array}{l}\text { Bulanık ANP, Bulanık TOPSIS, } \\
\text { Bulanık ELECTRE }\end{array}$ \\
\hline
\end{tabular}

Bu çalışmanın amacı ise bulanık VIKOR yönteminin personel seçim sürecinde kullanılabilecek etkin bir ÇKKV tekniklerinden biri olduğunu göstermek ve buna yönelik algoritma geliştirmektir. VIKOR yöntemi literatürde en çok kullanılan TOPSIS yönteminden farklı olarak kriterlerin sadece en iyi ve kötü performanstan uzaklıklarını değil, bu uzaklıkların göreli değerlerini de ölçmektedir ve daha iyi sonuçlar vermektedir.

Çalışmanın bundan sonra devam eden üçüncü bölümünün birinci kısmında bulanık küme teorisine ilişkin bilgiler verilmiş, ikinci kısmında VIKOR ve bulanık VIKOR yönteminden bahsedilmiştir. Çalışmanın dördüncü bölümünü oluşturan uygulama kısmında ise öncelikle personel seçimine ilişkin kriterler belirlenmiş ve bu kriterlere karar vericilerin verdikleri ağırlıklar tespit edilmiş, sonraki aşamada bu kriterlere göre adaylara puan verilmiştir. Bu ağırlıklar ve puan- lar bulanık sayılara dönüştürülmüştür. Daha sonra belirlenen kriterlere ve alınan puanlara göre VIKOR yöntemi kullanılarak adayların değerlendirilme süreci gerçekleştirilmiştir. Çalışmanın beşinci bölümünde ise çalışmanın genel değerlendirilmesi yapılmış ve çalışmanın farklı boyutlarda nasıl geliştirilebileceğine ilişkin bilgiler verilmiştir.

\section{YÖNTEM}

\subsection{Bulanık Küme Teorisi}

Bulanık küme, kesin sınırları olmayan, kademeli geçişleri öngören ve belirli üyelik derecelerine sahip olan elemanların oluşturduğu bir kümedir. Bu küme her biri 0 ile 1 arasında üyelik derecesine sahip bulanık sayılardan oluşan konveks bir yapıyı tanımlar ( $\mathrm{Hu}$, Wu ve Cai, 2009). Bu kümenin elemanlarının üyeliklerinin belirlenmesinde üye veya üye değildir gibi kesin ifadelerden ziyade üyelik fonksiyonları kullanılarak belirli üyelik dereceleri belirlenir(Zadeh, 1975).Üyelik 
fonksiyonlarının tanımlanmasında ise sayıların komşuluğu (yakınlığı) yaklaşımından yararlanılır ve üyelik fonksiyonları genellikle bu komşuluğun durumuna göre genellikle üçgen üyelik fonksiyonlar ve yamuk üyelik fonksiyonları ile gösterilir. Uygulamalarda çoğunlukla hesaplama kolaylığı açısından üçgen üyelik fonksiyonları tercih edilir. Bu çalışmada da üçgen üyelik fonksiyonu kullanıımıştır. üçgen üyelik fonksiyonudenklem 1'de tanımlanmıştır (Triantaphyllou, 2000).

$$
\mu_{A}(x)= \begin{cases}0, & x<a_{1} \\ \frac{x-a_{1}}{a_{2}-a_{1}}, & a_{1} \leq x \leq a_{2} \\ \frac{a_{3}-x}{a_{3}-a_{2}}, & a_{2} \leq x \leq a_{3} \\ 0, & x>a_{3}\end{cases}
$$

Denklem 1'de a $\tilde{A}$ bulanık sayısının alt değerini, $a_{2}$ orta değerini ve $a_{3}$ üst değerini göstermektedir. Geliştirilen bu formüle göre üçgen bulanık kümenin elemanları $\tilde{A}=\left(a_{1}, a_{2}, a_{3}\right)$ olarak gösterilir ve denklem 1'de verilmiş olan üçgen üyelik fonksiyonu ile tanımlanır. Buna göre $\tilde{A}$ üyelik fonksiyonu $\mu_{\tilde{A}}(x)=R \rightarrow[0,1]$ olarak belirlenir.

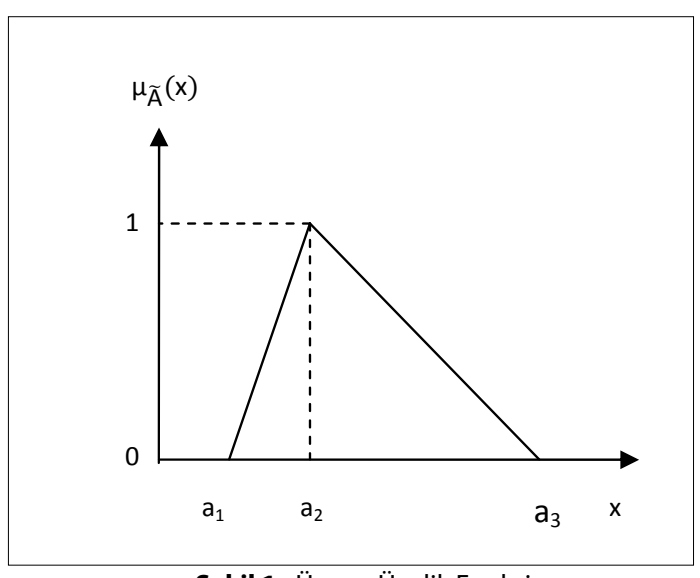

Şekil 1: Üçgen Üyelik Fonksiyonu

Bulanık sayılar aracılığıyla çok kötü, kötü, orta kötü, orta gibi net olarak tanımlanamayan dilsel değişkenlerin kantitatif karşılık değerleri bulunur (Zadeh, 1975). Örneğin, orta iyi dilsel değişkeninin üçgen bulanık sayı değerleri $(5,7,9)$ dur. Bu değişkenin üyelik fonksiyonu ise denklem 1' deki gösterime uygun olarak denklem 2'de gösterilmiştir.

$$
\mu_{A}(x)=\left\{\begin{array}{lc}
0, & x<5 \\
\frac{x-5}{7-5}, & 5 \leq x \leq 7 \\
\frac{9-x}{9-7}, & 7 \leq x \leq 9 \\
0, & x>9
\end{array}\right.
$$

Karar vericiler dilsel değişkenleri kullanarak karar kriterlerininönem düzeyini ve bu kriterlere göre alternatifleri değerlendirirler.

\section{VIKOR Yöntemi}

VIKOR yöntemi Opricovic (1988) tarafından geliştirilen özellikle sistem tasarımının başında karar vericinin tercihlerini belirleyememesi veya bilmemesi durumunda karar vermeye yardımcı olmak üzere geliştirilmiş niteliksel çoklu karar verme yöntemidir (Opricovic ve Tzeng, 2007). Yöntemin amacı, uzlaşmacı bir çözüm ile maksimumgrup faydası(çoğunluk kuralı) ve minimumbireyselpişmanlığı sağlayacak çok kriterli optimal uzlaşık birçözümbulmaktır. Uzlaşık çok kriterli çözüm, uzlaşık programlamada toplama fonksiyonu olarak kullanılan Lp kriterinden yararlanılarak geliştirilmiştir. i tane alternatifin $\mathrm{j}$ tane kritere göre ölçümü fij, kriter ağırlıkları ise wj ile gösterildiğinde Lpi ölçümü denklem 3'de görüldüğü gibi ifade edilecektir (Lai ve Hwang, 1996).Denklemde Lpi ölçümü, tüm alternatifler ile pozitif ideal çözüm arasındaki uzaklığın normalize edilmiş değerlerini vermektedir.

$$
\begin{aligned}
& L p_{i}=\left(\sum_{j=1}^{k}\left[w_{j}\left(f j^{*}-f_{i j}\right) /\left(f j^{*}-f j^{-}\right)\right]^{p}\right)^{\frac{1}{p}}(3) \\
& \mathrm{i}=1,2,3, \ldots \ldots, \mathrm{m}, \mathrm{j}=1,2,3 \ldots \ldots \mathrm{n} 1 \leq \mathrm{p} \leq \infty
\end{aligned}
$$

VIKOR yönteminde $L_{1 i}\left(S_{i}\right)$ ve $L_{\infty i}\left(R_{i}\right)$ sıralama kriterinin formülasyonunda kullanılır. min Si maksimum grup faydasını, min Ri ise minimum kişisel pişmanlığı göstermektedir ve uzlaşık sıralı çözüm ikisi arasında karşılıklı faydaların optimize edilmesiyle sağlanır. Buna göre uzlaşık çözüm $F^{c}$, şekil 2'de gösterildiği ideal $F^{*}$ değerlerine en yakın uygun çözümdür. Bu çözüm $\Delta f_{1}=f_{1}^{*}-f_{1}^{c}$ ile $\Delta f_{2}=f_{2}^{*}-f_{2}^{c}$ arasında dengeyi sağlayan bir yaklaşım sonucunda elde edilir (Opricovic e Tzeng, 2004).

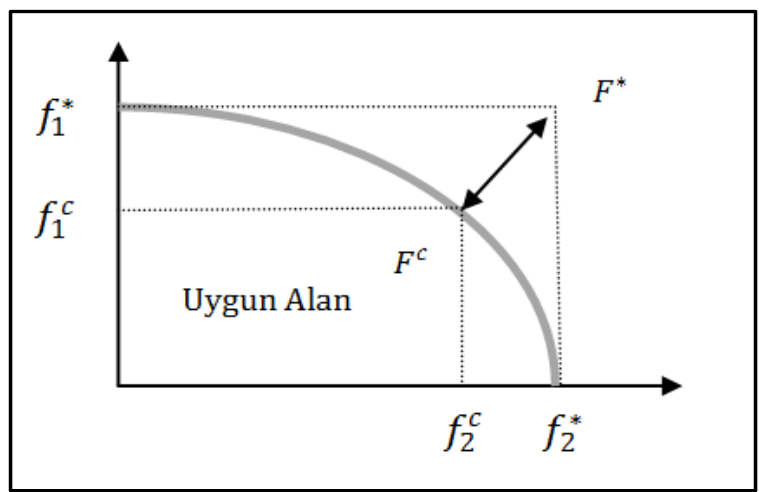

Şekil 2: İdeal ve Uzlaşık Çözümler (Kaynak: Opricovic ve Tzeng, 2004) 


\section{Bulanık VIKOR Yöntemi}

Klasik çok kriterli karar verme tekniklerinde kriter ağırlıklarının ve değerlendirmelerin kesin olarak bilindiği varsayılmaktadır. Ancak gerçek hayatta bazı durumlarda kesin ifadeler kullanmak mümkün olmamaktadır. Bu soruna çözüm olarak Fayed (1965) tarafından geliştirilen bulanık mantık teorisine dayalı bulanık kümelerden faydalanılabilir. Böylece kesin olarak ifade edilemeyen değişkenler dilsel değerlerle ifade edilebilir. Bu teori çok kriterli karar verme tekniklerinde kullanılmaya başlanarak bulanık ÇKKV teknikleri geliştirilmiştir. Bunlardan biri de bulanık VIKOR yöntemidir. Bulanık VIKOR, elde edilen bulanık karar matrisi değerlerini kullanarak aşağıdaki aşamaları içeren bir algoritmadan oluşmaktadır (Chen ve Wang, 2009).

Adım 1: Öncelikle problemin çözümü için k sayıda karar verici, $\mathrm{n}$ tane alternatif ve $\mathrm{m}$ tane kriter belirlenir.

Adım 2: Dilsel değişkenler ve bu değişkenlerin karşılıkları bulanık sayılar olarak tanımlanır. Dilsel değişkenler kriter ağırlıklarını belirlemek ve alternatifleri derecelendirmek için kullanılır.

Adım 3: wjkn tane karar vericiden oluşan bir kümede n'inci karar vericinin değerlendirdiği karar kriterinin önem ağırlığını; $\tilde{f}_{i j}$, j kriterine göre i alternatifinin derecesini göstersin. Karar kriterlerinin önem ağılıkları ve kriterler bazında alternatiflerin dereceleri (4) ve (5) no'lu eşitlikler kullanılarak her biri için tek bir değerlendirme olacak şekilde birleștirilir ve bütünleştirilmiş değerler elde edilir (Chen vd., 2006).

$$
\begin{aligned}
& \tilde{w}_{j}=\frac{1}{k}\left[\tilde{w}_{j}^{1}(+) \tilde{w}_{j}^{2}(+) \ldots(+) \tilde{w}_{j}^{k}\right] \\
& \tilde{f}_{i j}=\frac{1}{k}\left[\tilde{f}_{i j}^{1}(+) \tilde{f}_{i j}^{2}(+) \ldots(+) \tilde{f}_{i j}^{k}\right]
\end{aligned}
$$

Bu çalışmada sözel değişkenler $\tilde{f}_{i j}$ ve $\tilde{w}_{j}$ bulanık sayı ile gösterilmiştir.

Adım 4: Tüm kriter ve alternatifler için tek bir değer elde edildikten sonra, $i$ alternatifli ve $j$ kriterli $\tilde{D}$ bulanık karar matrisi ve Wjağırlık matrisi (6) no'lu eşitlikte gösterildiği şekilde oluşturulur.

$$
\begin{aligned}
& \tilde{D}=\left[\begin{array}{cccc}
\tilde{f}_{11} & \tilde{f}_{12} & \cdots & \tilde{f}_{1 j} \\
\tilde{f}_{21} & \tilde{f}_{22} & \cdots & \tilde{f}_{2 j} \\
\vdots & \vdots & \cdots & \vdots \\
\tilde{f}_{i 1} & \tilde{f}_{i 2} & \cdots & \tilde{f}_{m n}
\end{array}\right], \tilde{W}_{j}=\left[\tilde{w}_{1}, \tilde{w}_{2}, \ldots \ldots, \tilde{w}_{j}\right] \\
& \mathbf{i}=1,2, \ldots, \mathrm{m} ; \mathrm{j}=1,2 \ldots \ldots . \mathrm{n}
\end{aligned}
$$

$\tilde{\tilde{f}}_{i j}, i$ alternatifinin j. kritere göre derecesini ve $\tilde{w}_{j}$ ise j. kriterin önem ağırlığını göstermektedir.

Adım 5: Bulanık karar matrisinde j kriteri fayda açısından değerlendiriliyorsa tüm kriter fonksiyonlarının en iyi $\tilde{f}_{j}^{*}$ ve en kötü $\tilde{f}_{j}^{-}$değerleri eşitlik (7) kullanılarak belirlenir.

$$
\tilde{f}_{j}^{*}=\max _{j} \tilde{f}_{i j}, \tilde{f}_{j}^{-}=\min _{j} \tilde{f}_{i j}
$$

Adım 6: $\tilde{S}_{i}$ değerleri (8) no'lu denklem ve $\tilde{R}_{i}$ değerleri (9) no'lu denklem kullanılarak hesaplanır.

$$
\begin{aligned}
& \tilde{S}_{i}=\sum_{j=1}^{n}\left[\tilde{w}_{j}\left(\tilde{f}_{j}^{*}-\tilde{f}_{i j}^{*}\right) /\left(\tilde{f}_{j}^{*}-\tilde{f}_{j}^{-}\right)\right] \\
& \tilde{R}_{i}=\max _{j}\left[\tilde{w}_{j}\left(\tilde{f}_{j}^{*}-\tilde{f}_{i j}^{*}\right) /\left(\tilde{f}_{j}^{*}-\tilde{f}_{j}^{-}\right)\right]
\end{aligned}
$$

$\tilde{w}_{j}$, kriterlerin ağırlığını göstermektedir. $\tilde{S}_{i}$, tüm kriterlere göre i. alternatifin en iyi bulanık değere uzaklığının toplamıdır. $\tilde{R}_{i}$ ise j. kritere göre i. alternatifin en kötü bulanık değerlere olan maksimum uzaklığıdır. $\tilde{f}_{i j}^{*}, \mathrm{~A}_{\mathrm{i}}$ alternatifi için j kriteri açısından sıralama derecesini gösterir.

Adım 7: $S_{i}, S_{i}^{*}$ değerleri (10) no'lu eşitlik ve $R_{i^{\prime}}$ $R^{*}$, değerleri (11) no'lu eşitlik aracılığıyla hesaplanır.

$$
\begin{aligned}
& \tilde{S}_{i}^{*}=\min _{i} \tilde{S}_{i}, \tilde{S}_{i}^{-}=\max \tilde{S}_{i}, \\
& \tilde{R}_{i}^{*}=\min _{i} \tilde{R}_{i}, \tilde{R}_{i}^{-}=\max \tilde{R}_{i},
\end{aligned}
$$

$\tilde{S}_{i}^{*}$, maksimum çoğunluk kuralını ve $\tilde{R}^{*}$ ise farklı görüştekilerin minimum bireysel pişmanlığını ifade etmektedir. Bu hesaplamalardan sonra $\tilde{Q}_{i}$ indeksi(12) no'lu denklem kullanılarak elde edilir

$$
\tilde{Q}_{i}=v\left(\tilde{S}_{i}-\tilde{S}^{*}\right) /\left(\tilde{S}^{-}-\tilde{S}^{*}\right)+(1-v)\left(\tilde{R}_{i}-\tilde{R}^{*}\right) /\left(\tilde{R}^{-}-\tilde{R}^{*}\right)
$$

$\tilde{Q}_{i}$ indeksi, grup faydası ile bireysel pişmanlığı birlikte değerlendirilmesi ile hesaplanır. v değeri maksimum grup faydasını sağlayan stratejinin önemini ifade eder iken, 1-v bireysel pişmanlık değerini ifade eder. Uzlaşmacı çoğunluk için $v \approx 0.5$ alınabilir (Opricovic, 2011).

Adım 8: Bu aşamada bulanık sayıların ortalamaları alınarak durulaştırılmış ve $S_{i}, R_{i}$ ve $Q_{i}$ indeks değerleri bulunur. Daha sonra elde edilen indeks değerlerine göre alternatifler sıralanır. İndeks değeri en küçük olan en iyi alternatifi göstermektedir.

Adım 9: Bu aşamada belirlenen en iyi alternatifin uzlaştırıcı çözüm olup olmadığının belirlenmesi gerekir.Uzlaştırıcı en iyi çözümü belirlemek için aşağıdaki iki koşulun uygunluğu kontrol edilir.

1.Koşul: Kabul Edilebilir Avantaj: Bu koşul en iyi ve en yakın seçenek arasında belirgin bir fark olduğunun kanıtlanmasını içerir ve (13) no'lu eşitsizlikte gösterilmiştir. 
$\mathrm{Q}\left(\mathrm{A}^{\prime \prime}\right)-\mathrm{Q}\left(\mathrm{A}^{\prime}\right) \geq \mathrm{DQ}$

$D Q=\frac{1}{m-1} ; \mathrm{m}$ alternatif sayısını ifade eder.

$A^{\prime}$ değeri sıralamada birinci sırada yer alan alternatif ve $A$ "sıralamada en iyi ikinci alternatifi gösterir.

2.Koşul: Kabul Edilebilir İstikrar

Alternatif A, S ve/veya R değerlerine göre yapılan sıralamada en iyi alternatif olmalıdır (Opricovic ve Tzeng, 2004).

Eğer 1. koşul sağlanmaz ise $Q\left(A^{m}\right)-Q\left(A^{\prime}\right) \leq D Q$ ve olursa, $A^{(m)}$ ve $A^{\prime}$ aynı uzlaştırıcı çözüm olur.
Eğer 2. koşul kabul edilmezse, her ne kadar A" nın nispi bir avantajı olsa da karar vermede tutarsızlık vardır. Bundan dolayı A've A" uzlaştırıcı çözümleri aynıdır. $Q$ değeri minimum olan en iyi alternatifin seçimi yapılır.

\section{UYGULAMA}

Çalışmada bir teknoloji firmasının mühendis alma süreci bulanık VIKOR yöntemi kullanılarak incelenmiştir. Sürece yönelik olarak geliştirilen hiyerarşik yapı şekil 3'de gösterilmiştir.

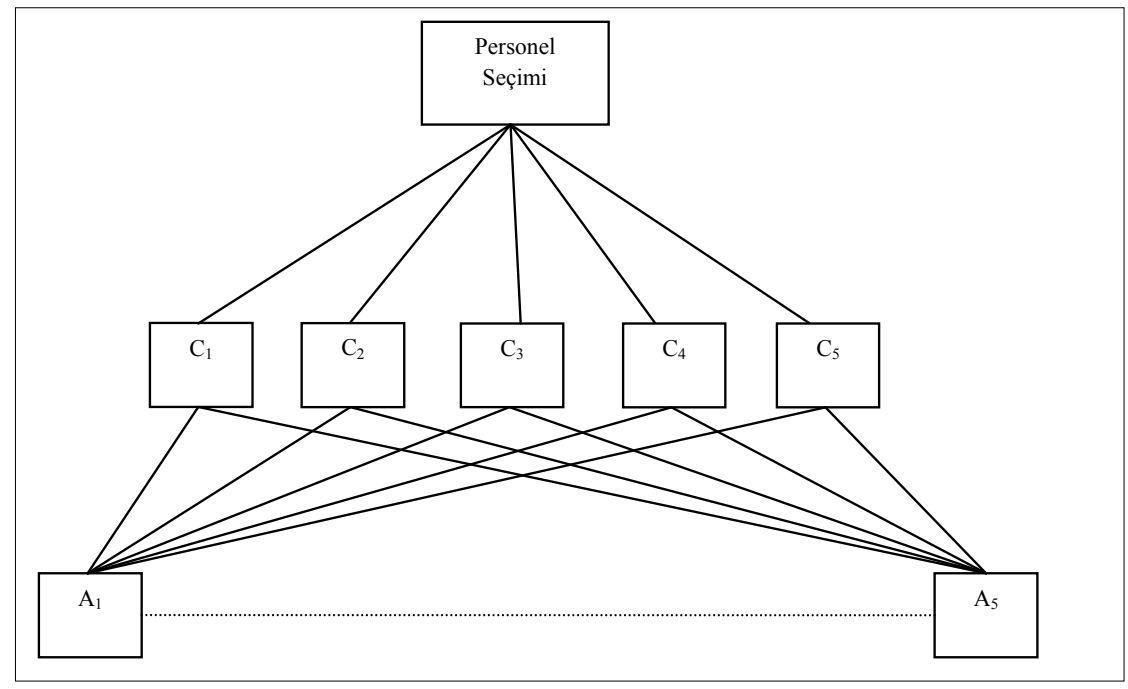

Şekil 3: Personel Seçim Sürecinin Hiyerarşik Yapısı

Personel seçimi için geliştirilen bulanık VIKOR ise aşağıdaki aşamaları içeren bir süreçtir.

Adım 1: Karar verici grubu oluşturulur ve adaylar belirlenir. Çalışmada bir insan kaynakları müdürü, bölüm müdürü ve bölüm şefi olmak üzere alanında uzman 3 kişilik bir karar verici grup oluşturulmuş ve 5 aday için değerlendirme yapılmıştır. Daha sonra incelenen literatür vekarar vericilerin görüşleri doğrultusunda Tablo 2'de gösterilen karar kriterleri belirlenmiştir.

Tablo 2: Karar Kriterleri

\begin{tabular}{|c|c|c|c|c|c|}
\hline \multirow{2}{*}{ Kriterler } & $C_{1}$ & $C_{2}$ & $C_{3}$ & $C_{4}$ & $C_{5}$ \\
\cline { 2 - 6 } & İş tecrübesi & Eğitim düzeyi & Yabancı dil & Aldığı Eğitimler & Sosyal İlişkiler \\
\hline
\end{tabular}

Adım 2: Bu aşamada kriterler ve alternatifleri de- lidir.Kullanılan dilsel değişkenler ve karşılıkları olan ğerlendirmek için uygun dilsel değişkenler seçilme- üçgen bulanık sayılar Tablo 3'de verilmiştir.

Tablo 3: Kriter ve Alternatifleri Değerlendirmek İçin Kullanılan Dilsel Değişkenler ve Bulanık Sayı Değerleri

\begin{tabular}{|c|c|c|c|}
\hline \multicolumn{2}{|c|}{ Kriter Ağırlıkları } & \multicolumn{2}{c|}{ Alternatiflerin Değerlendirmeleri } \\
\hline Dilsel Değişkenler & Bulanık Sayılar & Dilsel Değişkenler & Bulanık Sayılar \\
\hline Çok Düşük (ÇD) & $(0,0,0.1)$ & Çok Kötü (ÇK) & $(0,0,1)$ \\
\hline Düşük (D) & $(0,0.1,0.3)$ & Kötü (K) & $(0,1,3)$ \\
\hline Orta Düşük (OD) & $(0.1,0.3,0.5)$ & Orta Kötü (OK) & $(1,3,5)$ \\
\hline Orta (O) & $(0.3,0.5,0.7)$ & Orta (O) & $(3,5,7)$ \\
\hline Orta Yüksek (OY) & $(0.5,0.7,0.9)$ & Orta İyi (OI) & $(5,7,9)$ \\
\hline Yüksek (Y) & $(0.7,0.9,1.0)$ & İyi(I) & $(7,9,10)$ \\
\hline Çok Yüksek (ÇY) & $(0.9,1.0,1.0)$ & Çok İyi (Çi) & $(9,10,10)$ \\
\hline
\end{tabular}

(Kaynak: Chen, 2000) 


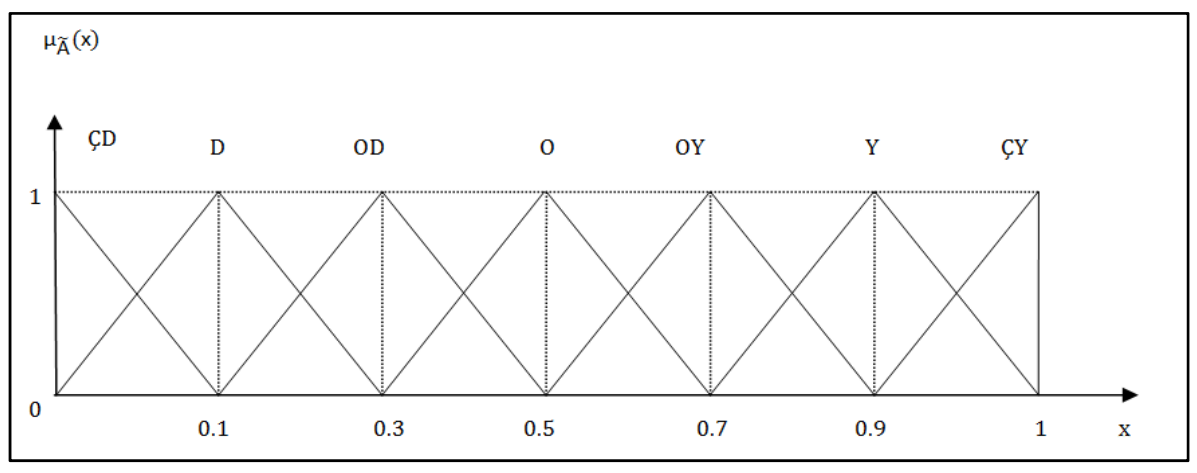

Şekil 4: Kriter Ağırıklarının Dilsel Değişkenler için Üyelik Fonksiyonları (Kaynak: Chen, 2000)

Kriter ağırlıklarının dilsel değişkenleri için üyelik fonksiyonları ise şekil 4'de gösterilmiştir.

Adım 3: Bu aşamada öncelikle karar vericilerin (KV) kriterler için verdikleri ağırlıklar ve kriterlere göre alternatiflere verdikleri değerlerin dilsel değişkenler cinsinden ifadesi sırasıyla Tablo 4 ve Tablo 5'de olduğu gibi belirlenmiştir.

Tablo 4: Karar Vericilerin Kriterlere Verdikleri Önem Ağırlıkları

\begin{tabular}{|l|l|l|l|l|l|}
\hline & $\mathrm{C}_{1}$ & $\mathrm{C}_{2}$ & $\mathrm{C}_{3}$ & $\mathrm{C}_{4}$ & $\mathrm{C}_{5}$ \\
\hline $\mathrm{KV}_{1}$ & $\mathrm{Y}$ & $\mathrm{Y}$ & $\mathrm{OY}$ & $\mathrm{O}$ & $\mathrm{Y}$ \\
\hline $\mathrm{KV}_{2}$ & $\mathrm{Y}$ & $\mathrm{OY}$ & $\mathrm{Ç}$ & $\mathrm{O}$ & $\mathrm{Y}$ \\
\hline $\mathrm{KV}_{3}$ & $\mathrm{C} \mathrm{Y}$ & $\mathrm{O}$ & $\mathrm{OY}$ & $\mathrm{OD}$ & $\mathrm{OY}$ \\
\hline
\end{tabular}

Tablo 5: Karar Vericiler Tarafından Alternatiflerin Değerlendirilmesi

\begin{tabular}{|c|c|c|c|c|c|c|}
\hline & & $\mathrm{C}_{1}$ & $\mathrm{C}_{2}$ & $\mathrm{C}_{3}$ & $\mathrm{C}_{4}$ & $\mathrm{C}_{5}$ \\
\hline \multirow{3}{*}{$A_{1}$} & $\mathrm{KV}_{1}$ & $i$ & oi & 0 & Çi & 0 \\
\hline & $\mathrm{KV}_{2}$ & oi & çi & $\mathrm{Oi}$ & çí & 0 \\
\hline & $\mathrm{KV}_{3}$ & oi & $\mathrm{Oi}$ & $\mathrm{OK}$ & çi & oi \\
\hline \multirow{3}{*}{$\mathrm{A}_{2}$} & $\mathrm{KV}_{1}$ & i & oi & $\mathrm{K}$ & $i$ & 0 \\
\hline & $\mathrm{KV}_{2}$ & oi & oi & çi & oi & $\mathrm{OK}$ \\
\hline & $\mathrm{KV}_{3}$ & 0 & $\mathrm{OK}$ & $\mathrm{K}$ & $\mathrm{i}$ & $\mathrm{OK}$ \\
\hline \multirow{3}{*}{$\mathrm{A}_{3}$} & $\mathrm{KV}_{1}$ & çi & $i$ & 0 & $i$ & $\mathrm{i}$ \\
\hline & $\mathrm{KV}_{2}$ & çi & çi & 0 & oi & çi \\
\hline & $\mathrm{KV}_{3}$ & $i$ & çi & $\mathrm{OK}$ & 0 & çi \\
\hline \multirow{3}{*}{$\mathrm{A}_{4}$} & $\mathrm{KV}_{1}$ & OK & OK & çi & OK & 0 \\
\hline & $\mathrm{KV}_{2}$ & OK & 0 & $i$ & 0 & 0 \\
\hline & $\mathrm{KV}_{3}$ & 0 & $\mathrm{OK}$ & $i$ & 0 & 0 \\
\hline \multirow{3}{*}{$\mathrm{A}_{5}$} & $\mathrm{KV}_{1}$ & $\mathrm{OK}$ & çi & oi & çأ & $\mathrm{OK}$ \\
\hline & $\mathrm{KV}_{2}$ & $\mathrm{OK}$ & çi & 0 & çiં & 0 \\
\hline & $\mathrm{KV}_{3}$ & 0 & $\mathrm{i}$ & 0 & $\mathrm{i}$ & 0 \\
\hline
\end{tabular}

Dilsel değişkenlerle ifade edilen bu değerlendir- değerlerine dönüştürülmüştür. Kriterlere ilişkin bulumeler daha sonra Tablo 3'de gösterilen bulanık sayı nan değerler 6 no' lu tabloda gösterilmiştir.

Tablo 6: Kriterlerin Bulanık Sayılarla Değerlendirilmesi

\begin{tabular}{|l|c|c|c|c|c|c|c|c|c|c|c|c|c|c|c|}
\hline Kriterler & \multicolumn{3}{|c|}{$\mathrm{C}_{1}$} & \multicolumn{3}{c|}{$\mathrm{C}_{2}$} & \multicolumn{3}{c|}{$\mathrm{C}_{3}$} & \multicolumn{3}{c|}{$\mathrm{C}_{4}$} & \multicolumn{3}{c|}{$\mathrm{C}_{5}$} \\
\hline $\mathrm{KV}_{1}$ & 0,7 & 0,9 & 1 & 0,7 & 0,9 & 1 & 0,5 & 0,7 & 0,9 & 0,3 & 0,5 & 0,7 & 0,7 & 0,9 & 1 \\
\hline $\mathrm{KV}_{2}$ & 0,7 & 0,9 & 1 & 0,5 & 0,7 & 0,9 & 0,9 & 1 & 1 & 0,3 & 0,5 & 0,7 & 0,7 & 0,9 & 1 \\
\hline $\mathrm{KV}_{3}$ & 0,9 & 1 & 1 & 0,3 & 0,5 & 0,7 & 0,5 & 0,7 & 0,9 & 0,1 & 0,3 & 0,5 & 0,5 & 0,7 & 0,9 \\
\hline Ort. & 0,77 & 0,93 & 1,00 & 0,50 & 0,70 & 0,87 & 0,63 & 0,80 & 0,93 & 0,23 & 0,43 & 0,63 & 0,63 & 0,83 & 0,97 \\
\hline
\end{tabular}

Alternatiflerin kriterler bazında değerlendirme sonuçlarının bulanık sayı değerleri ise Tablo 7'de gösterilmiştir.

Tablo 7: Karar Vericilerin Karar Kriterleri Bazında Alternatifleri Değerlendirmeleri

\begin{tabular}{|c|c|c|c|c|c|c|c|c|c|c|c|c|c|c|c|c|}
\hline & & \multicolumn{3}{|c|}{$C_{1}$} & \multicolumn{3}{|c|}{$C_{2}$} & \multicolumn{3}{|c|}{$C_{3}$} & \multicolumn{3}{|c|}{$C_{4}$} & \multicolumn{3}{|c|}{$C_{5}$} \\
\hline \multirow{3}{*}{$A_{1}$} & KV1 & 7 & 9 & 10 & 5 & 7 & 9 & 3 & 5 & 7 & 9 & 10 & 10 & 3 & 5 & 7 \\
\hline & KV2 & 5 & 7 & 9 & 9 & 10 & 10 & 5 & 7 & 9 & 9 & 10 & 10 & 3 & 5 & 7 \\
\hline & KV3 & 5 & 7 & 9 & 5 & 7 & 9 & 1 & 3 & 5 & 9 & 10 & 10 & 5 & 7 & 9 \\
\hline & Ort. & 5,67 & 7,67 & 9,33 & 6,33 & 8,00 & 9,33 & 3,00 & 5,00 & 7,00 & 9,00 & 10,00 & 10,00 & 3,67 & 5,67 & 7,67 \\
\hline \multirow{4}{*}{$A_{2}$} & KV1 & 7 & 9 & 10 & 5 & 7 & 9 & 0 & 1 & 3 & 7 & 9 & 10 & 3 & 5 & 7 \\
\hline & KV2 & 5 & 7 & 9 & 5 & 7 & 9 & 9 & 10 & 10 & 5 & 7 & 9 & 1 & 3 & 5 \\
\hline & KV3 & 3 & 5 & 7 & 1 & 3 & 5 & 0 & 1 & 3 & 7 & 9 & 10 & 1 & 3 & 5 \\
\hline & Ort. & 5,00 & 7,00 & 8,67 & 3,67 & 5,67 & 7,67 & 3,00 & 4,00 & 5,33 & 6,33 & 8,33 & 9,67 & 1,67 & 3,67 & 5,67 \\
\hline \multirow{4}{*}{$A_{3}$} & KV1 & 9 & 10 & 10 & 7 & 9 & 10 & 3 & 5 & 7 & 7 & 9 & 10 & 7 & 9 & 10 \\
\hline & KV2 & 9 & 10 & 10 & 9 & 10 & 10 & 3 & 5 & 7 & 5 & 7 & 9 & 9 & 10 & 10 \\
\hline & KV3 & 7 & 9 & 10 & 9 & 10 & 10 & 1 & 3 & 5 & 3 & 5 & 7 & 9 & 10 & 10 \\
\hline & Ort. & 8,33 & 9,67 & 10,00 & 8,33 & 9,67 & 10,00 & 2,33 & 4,33 & 6,33 & 5,00 & 7,00 & 8,67 & 8,33 & 9,67 & 10,00 \\
\hline \multirow{4}{*}{$\mathrm{A}_{4}$} & KV1 & 1 & 3 & 5 & 1 & 3 & 5 & 9 & 10 & 10 & 1 & 3 & 5 & 3 & 5 & 7 \\
\hline & KV2 & 1 & 3 & 5 & 3 & 5 & 7 & 7 & 9 & 10 & 3 & 5 & 7 & 3 & 5 & 7 \\
\hline & KV3 & 3 & 5 & 7 & 1 & 3 & 5 & 7 & 9 & 10 & 3 & 5 & 7 & 3 & 5 & 7 \\
\hline & Ort. & 1,67 & 3,67 & 5,67 & 1,67 & 3,67 & 5,67 & 7,67 & 9,33 & 10,00 & 2,33 & 4,33 & 6,33 & 3,00 & 5,00 & 7,00 \\
\hline \multirow{4}{*}{$A_{5}$} & KV1 & 1 & 3 & 5 & 9 & 10 & 10 & 5 & 7 & 9 & 9 & 10 & 10 & 1 & 3 & 5 \\
\hline & KV2 & 1 & 3 & 5 & 9 & 10 & 10 & 3 & 5 & 7 & 9 & 10 & 10 & 3 & 5 & 7 \\
\hline & KV3 & 3 & 5 & 7 & 7 & 9 & 10 & 3 & 5 & 7 & 7 & 9 & 10 & 3 & 5 & 7 \\
\hline & Ort. & 1,67 & 3,67 & 5,67 & 8,33 & 9,67 & 10,00 & 3,67 & 5,67 & 7,67 & 8,33 & 9,67 & 10,00 & 2,33 & 4,33 & 6,33 \\
\hline
\end{tabular}


Adım 4:Bu aşamada kriterlerin bulanık sayı değerleri (4) no'lu denklem kullanılarak Tablo 6'da gösterilen KV'lerin kriter ağırlıklarının ortalama değerleri hesaplanarak bütünleştirilmiş bulanık ağırlıklar elde edilmiş ve sonuçlar ve Tablo 8'de gösterilmiştir.

Tablo 8: Bütünleştirilmiş Bulanık Ağırlıklar

\begin{tabular}{|c|c|c|c|}
\hline Kriterler & \multicolumn{3}{|c|}{ Bulanık Ağırlıklar $\left(\mathrm{W}_{\mathrm{j}}\right)$} \\
\hline $\mathrm{C}_{1}$ & 0,77 & 0,93 & 1 \\
\hline $\mathrm{C}_{2}$ & 0,5 & 0,7 & 0,87 \\
\hline $\mathrm{C}_{3}$ & 0,63 & 0,8 & 0,93 \\
\hline $\mathrm{C}_{4}$ & 0,23 & 0,43 & 0,63 \\
\hline $\mathrm{C}_{5}$ & 0,63 & 0,83 & 0,97 \\
\hline
\end{tabular}

Kriter değerleri incelendiğinde, en önemli kriterin diğer bir deyişle en fazla ağırlık verilen kriterin iş tecrübesi (C1) olduğu, en az önem verilen kriterin ise adayın aldığı eğitimler olduğu görülmektedir. Bunun nedeni, firmanın çalışanlarına sürekli eğitim vererek bu açığı kapatabileceğidir.

Benzer şekilde her bir alternatifin kriterler bazında bütünleştirilmiş bulanık sayı değerleri (5) no'lu denklem kullanılarak Tablo 7'de gösterilen ortalama değerlere ulaşılmıştır. Elde edilen ortalama değerlerden bulanık karar matrisi elde edilmiştir ve sonuçlar Tablo 9'da gösterilmiştir.

Tablo 9: Bulanık Karar Matrisi

\begin{tabular}{|c|c|c|c|c|c|c|c|c|c|c|c|c|c|c|c|}
\hline Kriterler & \multicolumn{3}{|c|}{$A_{1}$} & \multicolumn{3}{|c|}{$A_{2}$} & \multicolumn{3}{|c|}{$\mathrm{A}_{3}$} & \multicolumn{3}{|c|}{$A_{4}$} & \multicolumn{3}{|c|}{$\mathrm{A}_{5}$} \\
\hline$C_{1}$ & 5,67 & 7,67 & 9,33 & 5,00 & 7,00 & 8,67 & 8,33 & 9,67 & 10,00 & 1,67 & 3,67 & 5,67 & 1,67 & 3,67 & 5,67 \\
\hline$C_{2}$ & 6,33 & 8,00 & 9,33 & 3,67 & 5,67 & 7,67 & 8,33 & 9,67 & 10,00 & 1,67 & 3,67 & 5,67 & 8,33 & 9,67 & 10,00 \\
\hline$C_{3}$ & 3,00 & 5,00 & 7,00 & 3,00 & 4,00 & 5,33 & 2,33 & 4,33 & 6,33 & 7,67 & 9,33 & 10,00 & 3,67 & 5,67 & 7,67 \\
\hline $\mathrm{C}_{4}$ & 9,00 & 10,00 & 10,00 & 6,33 & 8,33 & 9,67 & 5,00 & 7,00 & 8,67 & 2,33 & 4,33 & 6,33 & 8,33 & 9,67 & 10,00 \\
\hline$C_{5}$ & 3,67 & 5,67 & 7,67 & 1,67 & 3,67 & 5,67 & 8,33 & 9,67 & 10,00 & 3,00 & 5,00 & 7,00 & 2,33 & 4,33 & 6,33 \\
\hline
\end{tabular}

Adım 5: Tüm kriter fonksiyonlarının en iyi $\left(\tilde{f}_{j}^{*}\right)$ ve en kötü değerleri $\left(\tilde{f}_{j}^{-}\right)(7)$ no'lu eşitlik yardımıyla bulunmuş ve sonuçlar Tablo 10'da gösterilmiştir.

Tablo 10: Kriterlerin En İyi ve En Kötü Değerleri

\begin{tabular}{|c|c|c|c|c|c|c|}
\hline Kriterler & \multicolumn{3}{|c|}{$\left(\tilde{\mathrm{f}}_{\mathrm{j}}^{*}\right)$} & \multicolumn{3}{|c|}{$\left(\tilde{\mathrm{f}}_{\mathrm{j}}^{-}\right)$} \\
\hline $\mathrm{C}_{1}$ & 8,33 & 9,67 & 10,00 & 1,67 & 3,67 & 5,67 \\
\hline $\mathrm{C}_{2}$ & 8,33 & 9,67 & 10,00 & 1,67 & 3,67 & 5,67 \\
\hline$C_{3}$ & 7,67 & 9,33 & 10,00 & 2,33 & 4,00 & 5,33 \\
\hline$C_{4}$ & 9,00 & 10,00 & 10,00 & 2,33 & 4,33 & 6,33 \\
\hline$C_{5}$ & 8,33 & 9,67 & 10,00 & 1,67 & 3,67 & 5,67 \\
\hline
\end{tabular}

Adım 6: Tüm kriterlere göre i. alternatifin en iyi bulanık değere uzaklığının toplamını veren $\tilde{S}_{i}$ değerleri (8) no'lu denklem kullanılarak bulunmaktadır. Örneğin $A_{1}$ alternatifinin birinci bulanık sayısına ait $S_{i}$ değeri aşağıda gösterildiği şekilde hesaplanmıştır.

$S_{A 1}=(0,77 *(8,33-5,67) /(8,33-1,67))+(0,50 *(8,33-$ $6,33) /(8,33-1,67))+(0,63 *(7,67-3,00) /(7,67-$ $2,33))+(0,23 *(9-9) /(9-2,33))+(0,63 *(8,33-3,67) / 8,33-$ $1,67))=1,45$

Benzer şekilde her bir kriter bazında diğer alternatiflere ait $\tilde{S}_{i}$ ler hesaplanmış ve Tablo 11 'deki sonuçlar elde edilmiştir.

Tablo11: Alternatiflerin $\widetilde{S}_{i}$ Değerleri

\begin{tabular}{|c|c|c|c|c|}
\hline Alternatif & \multicolumn{3}{|c|}{$\widetilde{S}_{i}$} & Si Ort. \\
\hline$A_{1}$ & 1,45 & 1,71 & 1,41 & 1,52 \\
\hline$A_{2}$ & 2,01 & 2,64 & 2,73 & 2,46 \\
\hline$A_{3}$ & 0,77 & 0,98 & 0,96 & 0,90 \\
\hline$A_{4}$ & 2,01 & 2,71 & 3,17 & 2,63 \\
\hline$A_{5}$ & 1,83 & 2,24 & 2,29 & 2,12 \\
\hline
\end{tabular}

Her bir kritere göre i. alternatifin en kötü bulanık değerlere olan maksimum uzaklığını veren $\tilde{R}_{i}$ değeri de (9) no'lu denklem aracılığıyla hesaplanmıştır. Benzer şekilde $A_{1}$ alternatifinin birinci bulanık sayısına ait $R_{i}$ değeri aşağıda gösterildiği şekilde hesaplanmıştır.

$\mathrm{R}_{\mathrm{i}}=\operatorname{Max}\left(\left(0,77^{*}(8,33-5,67) /(8,33-1,67)\right),(0,50 *(8,33-\right.$ $6,33) /(8,33-1,67)), 0,63^{*}(7,67-3,00) /(7,67-2,33),\left(0,23^{*}(9-\right.$ 9)/(9-2,33)), $(0,63 *(8,33-7,11) / 8,33-1,67))=0,55$

Diğer alternatifler için de herbir kriter bazında aynı hesaplamalar yapılmış ve Tablo12'deki değerlere ulaşılımıştır.

Tablo12: Alternatiflerin $\widetilde{\mathrm{R}}_{\mathrm{i}}$ Değerleri

\begin{tabular}{|c|c|c|c|c|}
\hline Alternatif & \multicolumn{3}{|c|}{$\tilde{\mathrm{R}}_{\mathrm{i}}$} & Ri Ort. \\
\hline $\mathrm{A}_{1}$ & 0,55 & 0,65 & 0,60 & 0,60 \\
\hline $\mathrm{A}_{2}$ & 0,63 & 0,83 & 0,97 & 0,81 \\
\hline $\mathrm{A}_{3}$ & 0,63 & 0,75 & 0,73 & 0,70 \\
\hline $\mathrm{A}_{4}$ & 0,77 & 0,93 & 1,00 & 0,90 \\
\hline $\mathrm{A}_{5}$ & 0,77 & 0,93 & 1,00 & 0,90 \\
\hline
\end{tabular}

Adım 7: Bu aşamada maksimum grup faydası $\left(\tilde{S}^{*}\right)$ ile minimum bireysel pişmanlığı ( $\left.\tilde{R}^{*}\right)$ bir arada değerlendiren ve uzlaşık bir çözüm veren $\tilde{Q}_{i}$ değeri (12) no'lu denklem kullanılarak hesaplanmıştır.

$\tilde{Q}_{i}$ değerinin hesaplanması için gerekli olan $\tilde{S}_{i}^{-}$ ve $\tilde{S}_{i}^{*}$ değerleri (10) no lu denklem ve Tablo 11 'de verilen $\tilde{S}_{i}^{*}$ değerlerinden yararlanılarak bulunmuş ve Tablo $13^{\prime}$ de gösterilmiştir.

Tablo 13: $\widetilde{S}_{i}^{*}$ ve $\widetilde{S}^{-}$Değerleri

\begin{tabular}{|c|c|c|c|}
\hline$\widetilde{S}^{*}{ }_{i}$ (Min.) & 0,77 & 0,98 & 0,96 \\
\hline$\widetilde{S}^{-}{ }_{i}$ (Mak.) & 2,01 & 2,71 & 3,17 \\
\hline
\end{tabular}


$\tilde{R}_{i}^{*}$ ve $\tilde{R}_{i}^{-}$değerleri (11) no'lu denklem ve Tablo12'de bulunan $R_{\mathrm{i}}$ değerleri kullanılarak bulunmuştur.

Tablo 14: $\tilde{R}^{*}$ ve $\widetilde{R}^{-}$Değerleri

\begin{tabular}{|l|l|l|l|}
\hline$\tilde{R}^{*}$ (Min.) & 0,55 & 0,65 & 0,60 \\
\hline$\widetilde{R}^{-}$(Mak.) & 0,77 & 0,93 & 1,00 \\
\hline
\end{tabular}

Bu değerleri elde ettikten sonra $A_{1}$ alternatifinin birinci bulanık sayı değeri için $\tilde{Q}_{i}$ değeri (12) no'lu denklem kullanılarak aşağıdaki şekilde hesaplanmıştır.

$$
\mathrm{Q}_{\mathrm{A} 1}=0,5(1,45-0,77) /(2,01-0,77)+0,5(0,55-0,55) /
$$

$(0,77-0,55)=0,275$

Benzer hesaplama şekli kullanılarak kriterler bazında tüm alternatifler için

$\tilde{Q}_{i}$ uzlaşık çözüm değerleri elde edilmiştir. Elde edilen sonuçlar tablo 15 'de gösterilmiştir.

Tablo 15: Alternatiflerin $\widetilde{Q}_{i}$ Değerleri

\begin{tabular}{|c|l|l|l|l|}
\hline Alternatif & \multicolumn{3}{|c|}{$\widetilde{\mathrm{Q}}_{\mathrm{i}}$} & Ortalama \\
\hline $\mathrm{A}_{1}$ & 0,275 & 0,211 & 0,101 & 0,196 \\
\hline $\mathrm{A}_{2}$ & 0,681 & 0,802 & 0,864 & 0,782 \\
\hline $\mathrm{A}_{3}$ & 0,179 & 0,178 & 0,165 & 0,174 \\
\hline $\mathrm{A}_{4}$ & 0,999 & 1,000 & 1,000 & 1,000 \\
\hline $\mathrm{A}_{5}$ & 0,929 & 0,866 & 0,800 & 0,865 \\
\hline
\end{tabular}

Adım 8: Bu aşamada bulanık sayılarınortalamaları alınarak durulaştırılmış ve $S_{i^{\prime}} R_{i}$ ve $Q_{i}$ indeks değerleri bulunmuştur. Elde edilen ortalama sonuçlar Tablo 16 'da gösterilmiştir. Bulunan indeks değerlerine göre alternatifler arasında küçükten büyüğe doğru bir sıralama yapılmıştır. İndeks değeri en küçük olan en iyi alternatifi göstermektedir.

Tablo 16: $Q_{i}, S_{i}$ ve $R_{i}$ İndeks

Değerleri ve Alternatiflerin Sıralanması

\begin{tabular}{|c|l|c|l|c|l|c|}
\hline & \multicolumn{2}{|c|}{$\mathrm{Q}_{\mathrm{i}}$} & \multicolumn{2}{c|}{$\mathrm{S}_{\mathrm{i}}$} & \multicolumn{2}{c|}{$\mathrm{R}_{\mathrm{i}}$} \\
\hline & İndeks & Sira & İndeks & Sira & Indeks & Sira \\
\hline $\mathrm{A}_{1}$ & 0,196 & 2 & 1,522 & 2 & 0,599 & 1 \\
\hline $\mathrm{A}_{2}$ & 0,782 & 3 & 2,460 & 4 & 0,811 & 3 \\
\hline $\mathrm{A}_{3}$ & 0,174 & 1 & 0,902 & 1 & 0,703 & 2 \\
\hline $\mathrm{A}_{4}$ & 1,000 & 5 & 2,628 & 5 & 0,901 & 4 \\
\hline $\mathrm{A}_{5}$ & 0,865 & 4 & 2,121 & 3 & 0,901 & 4 \\
\hline
\end{tabular}

Adım 9: Bulunan $Q_{i}$ indeks değerine sahip $A_{3}$ alternatifi en iyi çözümdür. Ancak en iyi uzlaştırıcı çözümü sağlayıp sağlamadığını belirlemek için aşağıdaki iki koşulun uygunluğu kontrol edilmiştir.

1.Koşul: Kabul Edilebilir Avantaj: 12. eşitliğe göre; $Q\left(A^{\prime \prime}\right)-Q\left(A^{\prime}\right) \geq 0.25$ koşulu sağlanmalıdır. Tablo 16 'ye göre $0.196-0.174 \leq 0.25$ olduğundan $A_{3}$ alternatifi kabul edilebilir avantaj koşulunu sağlamamaktadır.
2.Koşul: Kabul Edilebilir İstikrar: Bu koşula göre $A^{\prime}$ alternatifinin $S$ ve/veya $R$ indeks değerlerine göre sıralamada en iyi alternatif olmalıdır. Tablo 16 incelendiğinde $\mathrm{A}_{3}$ alternatifinin $\mathrm{S}$ indeks değerlerine göre birinci sırada yer aldığı görülmektedir. Böylece alternatif kabul edilebilir istikrar koşulunu sağlamaktadır.

A1 alternatifi için 1. koşul sağlanmadığından $Q\left(A^{m}\right)-Q\left(A^{\prime}\right) \leq D Q$ kontrolü yapılmalı ve $A^{(m)}$ ve $A^{\prime}$ aynı uzlaştırıcı çözüm bulunmalıdır. Buna göre $Q_{A}{ }^{3}$ ile alternatifi ile $Q_{A}{ }^{1}$ alternatifi arasındaki fark $0.25^{\prime}$ ten düşüktür. Bu nedenle $A_{3}$ ve $A_{1}$ alternatifleri uzlaşık çözüm alternatifleri olarak kabul edilmelidir.

$Q_{i}, S_{i}$ ve $R_{i}$ değerlerine göre yapılan sıralamalar bir bütün olarak Tablo 17'de verilmiştir.

Tablo 17: $Q_{i}, S_{i}$ ve $R_{i}$ Değerlerine Göre Alternatiflerin Sıralaması

\begin{tabular}{|l|l|}
\hline$Q_{i}$ & $A_{3}>A_{1}>A_{2}>A_{5}>A_{4}$ \\
\hline$S_{i}$ & $A_{3}>A_{1}>A_{5}>A_{2}>A_{4}$ \\
\hline$R_{i}$ & $A_{1}>A_{3}>A_{2}>A_{4}=A_{5}$ \\
\hline
\end{tabular}

Tablo 17 sonucuna göre $Q_{i}$ ve $S_{i}$ değerlendirmeleri birbirine çok yakın sonuçlar verirken $R_{\mathrm{i}}$ değerlendirmesi farklı çıkmıştır. Ancak her üç değerlendirme de ilk iki sırada $A_{3}$ ve $A_{1}$ alternatiflerinin yer aldığı görülmektedir. Dolayısıyla tek bir adayın seçilmesi durumunda $A_{3}$ alternatifi, iki adayın seçilmesi durumunda $A_{3}$ ve $A_{1}$ adaylarının birlikte seçilmesi gerekmektedir.

\section{SONUÇ}

Günümüz işletmeleri için sahip oldukları personel işletmenin en önemli varlık kalemleri içinde yer almaktadır. Ancak günümüzde bu personelin sayısından ziyade personelin sahip oldukları özellikler ve işletmeye katabilecekleri katma değerler ön plana çıkmaktadır. Uygun personelin seçimi işletmelerin rekabet gücünü korumasını sağlayacaktır. Ancak bu süreç farklı görüşlere, farklı değerlendirmelere sahip birden fazla karar verici tarafından gerçekleştirilmeye çalışılmaktadır. Ayrıca belirlenen kriterlerin birçoğunun da nitel değerlerle ifade edilmesi gerekmektedir. Bu nedenle personel seçiminin bilimsel tabanlı yöntemlerle sistematik bir biçimde gerçekleştirilmesini sağlayacaktır. Bulanık çok kriterli karar verme yöntemleri bu süreçte karar vericiye yardımcı olmak amacıyla geliştirilen yöntemlerdir. Bulanık VIKOR yöntemi de son zamanlarda en çok kullanılan yöntemlerden biri olmuştur. 
Çalışmada personel seçim sürecinde bu yöntemin nasıl kullanılabileceği gösterilmiştir. Bu kapsamda bir teknoloji firmasının belirlenen kriterler ve kriterlere verilen ağırlıklar çerçevesinde 5 aday mühendis arasından aldıkları puana göre bir sıralama yapılmıştır. Çalışmada kriterler için verilen değerler (ağırlıklar) incelendiğinde iş tecrübesinin en önemli kriter olduğu, alınan eğitimlerin ise daha az dikkate değer bulunan bir kriter olduğu belirlenmiştir. Elde edilen performans skorları incelendiğinde ise $Q$ indeksine göre $A_{3}$ alternatifi en iyi alternatif olarak bulunmuştur.

Bir teknoloji firmasındaki mühendislik seçimine yönelik olarak geliştirilen bu çalışma, benzer algoritmayı kullanarak diğer tüm işletmeler ve kurumlar tarafından yararlanılabilir. Ayrıca bu algoritma kullanı- larak bir bilgisayar programı geliştirildiğinde bir karar destek sistemi olarak kullanabilir. Böylece sistemin karar değişkenleri üzerinde küçük değişiklikler yapılarak sürecin daha hızlı ve etkin olarak gerçekleştirilmesi sağlanabilir.

Bu çalışmanın uzantısı olarak farklı boyutta çalışmalar da yapılabilir. Örneğin bulanık kümenin üçgen üyelik fonksiyonu yerine dilsel değişkenlerin üç değil dört parametre değeri alabileceği yamuk üyelik fonksiyonları tanımlanarak farklı bir bulanık küme matrisi elde edilebilir. Karar verici sayısı, karar kriter sayısı ve ağırlık değerleri değiştirilerek duyarlılık analizi yapıIıp sonuçlardaki değişimler incelenebilir. Ayrıca diğer bulanık ÇKKV teknikleri ile karşılaştırılarak sonuçlar arasında farklılıklar ortaya konabilir. 


\section{KAYNAKLAR}

Afshari, A., Majid, M. ve Rosnah, M.Y. (2010) "Simple Additive Weighting Approach to Personnel Selection Problem" International Journal of Innovation, Management and Technology, 1(5):511-515.

Başkaya, Z. ve Öztürk, B. (2011) "Bulanık TOPSIS ile Satış Elemanı Adaylarının Değerlendirilmesi” Business and Economics Research Journal, 2(2):77-100.

Chen, C.T. (2000) "Extensions of the TOPSIS for Group Decision Making Under Fuzzy Environment" Fuzzy Sets and Systems, 114:1-9.

Chen, L.Y. ve Wang, T.C. (2009) "Optimizing partners' choice in IS/IT Outsourcing Projects: The Strategic Decision of Fuzzy VIKOR" International Journal of Production Economics, 120:233-242.

Chen, T.C., Ching-Torng Li. ve Huang, S.F. (2006) "A Fuzzy Approach for Supplier Evaluation and Selection in Supply Chain Management" International Journal of Production Economics, 102:289-301.

Dereli, T., Durmuşoğlu A., Seçkiner S.U. ve Avlanmaz, N. (2010) "A Fuzzy Approach for Personnel Selection Process" Turkish Journal of Fuzzy Systems, 1(2):126-140.

Dursun, E.M. ve Karsak, E.E. (2010) "A Fuzzy MCDM Approach for Personel Selection" Expert Systems with Applications, 37:4324-4330.

Ecer, F. (2006) "Bulanık Ortamlarda Grup Karar Vermeye Yardımcı Bir Yöntem: Fuzzy TOPSIS ve Bir Uygulama" İsletme Fakültesi Dergisi, 7(2):77-96.

El-Santawy, M.F. (2012) "A VIKOR Method for Solving Personnel Training Selection Problem" International Journal of Computing Science, 1(2):9-12.

Ersoylu, İ. (2011) "Bulanı VIKOR ve Bulanık AHP Yöntemleri ile Performans Ölçümü”, Yayınlanmamış Yüksek Lisans Tezi, İstanbul, Havacllı ve Uzay Teknolojileri Enstitüsü.

Fishburn, P.C. (1967) "Methods of Additive Utilities" Management Science 13:435-453.

Hu, Y., Wu, S. ve Cai, L. (2009) "Fuzzy Multicriteria Decision Making TOPSIS for Distribution Center Location Selection"International Conference on Networks Security, Wireless Communications and Trusted Computing.

Hwang, C.L. ve Yoon, K. (1981) "Multiple Attributes Decision Making Methods and Applications" Springer, Berlin Heidelberg.

Kabak, M. ve Kazançoğlu, Y. (2012) "Bulanık Analitik Hiyerarşi Yöntemiyle Öğretmen Seçimi ve Bir Uygulama" Afyon Kocatepe Üniversitesi İktisadi ve İdari Bilimler Fakültesi Dergisi, 14(1):95-111.
Kabak, M., Burmaoğlu S. ve Kazançoğlu, Y. (2012) "A Fuzzy HybridMCDM Approach for Professional Selection" Expert Systems with Applications 39:3516-3525.

Kelemenis, A. ve Askounis D. (2010) "A new TOPSISBased Multicriteria Approach Personnel Selection" Expert Systems with Applications, 37:4999-5008.

Lai, Y. ve Hwang C. (1996) Fuzzy Multiple Objective Decision Making: Methods and Applications, Lecture Notes in Economics and Mathematical Systems, Springer.

Nasab, F.G. ve Rostamy-Malkhalifeh, M. (2010) "Extension of TOPSIS for Group Decision Making Based on the Type-2 fuzzy Positive and Negative Ideal Solutions" Internetional Industrial Mathematics, 2(3):199-213.

Opricovic, S. (1998) "Multi-criteria Optimization of Civil Engineering Systems", Faculty of Civil Engineering, Belgrade.

Opricovic, S. (2011) "Fuzzy VIKOR With an Application to Water Resources Planning" Expert Systems with Applications, 38:12983-12990.

Opricovic, S. ve Tzeng, G.H. (2004) "The Compromise Solution by MCDM Methods: A Comparative Analysis of VIKOR and TOPSIS" European Journal of Operational Research, 156(2):445-455.

Opricovic, S. ve Tzeng, G.H. (2007) "Extended VIKOR Method in Comparison with Outranking Methods" European Journal of Operational Research, 178(2):514-529.

Özkan, Ö. (2007) "Personel Seçiminde Karar Verme Yöntemlerinin İncelenmesi: AHP, ELECTRE ve TOPSIS Örneği” Yayınlanmamış Yüksek Lisans Tezi, İzmir Dokuz Eylül Üniversitesi Sosyal Bilimler Enstitüsü.

Saaty, T.L. (1980) The Analytic Hiearchy Process, New York, McGraw-Hill.

Saaty, T.L. (1996) Decision Making with Dependence and Feedback: The Analytic Network Process, Pittsburgh, RWS Publications.

Saghafian, S. ve Hejazi S.R. (2005) "Multicriteria Group Decision Making Using A Modified Fuzzy TOPSIS Procedure" Proceedings of the 2005 International Conference on Computational Intelligence for Modelling, Control.

Zadeh, L.A.(1965) "Fuzzy Sets" Information and Control, 8:338-383.

Zadeh, L.A. (1975) "The Concept of Linguistic Variable and its Application to Approximate Reasoning 1"Information Sciences, 8:199-249. 